\title{
Russian converbs - temporal interpretation and information structure
}

\section{Abstract}

This paper presents a study of Russian converb constructions (non-finite verb forms used for adverbial subordination) and their interpretations, addressing the question of whether their semantic diversity could be explained in terms of vagueness (i.e. converbs are assumed to have one basic (vague) meaning, but may receive additional readings as a result of various linguistic as well as extra-linguistic factors) or polysemy (i.e. converb meanings can only be analyzed by listing all the different interpretations as a disjunction). Using compositional semantics, I present a temporal calculus for Russian converb sentences, arguing for a unified account of the semantics of converbs (a temporal overlap relation attributed to the converb suffix '-(j)a' and the meaning of temporal anteriority encoded by the converb suffix ' $-\mathrm{v}$ '). I conclude that these temporal meanings are the basic vague meanings of the two converb constructions, even though their realization is subject to constraints imposed by co-text or context.

\section{Introduction}

Following recent work on adverbial participles - e.g. Fabricius-Hansen and Haug (forthcoming) - I assume converbs to be a subgroup of open adjuncts (i.e. adjuncts without an overt subject) attached to the main predication at some level (e.g. VP, clause, or clause-externally). Such adjuncts introduce an eventuality that is co-eventive with the matrix event (i.e. being spacio-temporally collocated, having one common participant, or relating in some salient way to the matrix clause event). Converbs are open adjuncts headed by non-finite, verbal forms and are used primarily for adverbial subordination (Haspelmath 1995, 3).

The Russian converb construction (CC), also known as deepričastie, gerund or the adverbial participle of Russian, has two distinct forms - expressed by the morphemes '-v(ši)' and '-(j)a' depending on whether they combine with a verb stem in the Perfective (PF) or the Imperfective (IPF) aspectual form, respectively, cf. examples (1-2) from the original Russian data with the corresponding authorized English translations from the RuN corpus ${ }^{1}$ :

$$
\begin{aligned}
& \text { Ona, pro-čita-v, kiv-nu-la. } \\
& \text { she } \quad \text { PF-read-CONV nod-PF-PST } \\
& \text { 'She read it and nodded.' } \\
& \text { Valerij molča-l, vgljad-yva-ja-s'. } \\
& \text { Valerij be.silent-PST peer-IPF-CONV-REFL } \\
& \text { 'Valerii said nothing, peering.' }
\end{aligned}
$$

Converbs are often said to have an underspecified semantics as their interpretation depends largely on the interaction of various factors: (i) purely linguistic - e.g. formal (morphological) properties (language-specific), lexical semantics of the converb and the main verb, structural properties (position in the sentence), and (ii) extra-linguistic factors - e.g. logical relations, world knowledge, etc. The main question addressed in this paper concerns the interpretation of Russian converbs, and whether their semantic diversity should be attributed to vagueness (a view according to which there is just one basic (invariant) meaning but with a possibility to express additional meanings depending on the interaction of various linguistic and extra-linguistic factors) or polysemy (i.e. assuming that converbs have multiple inherent meanings, so that the semantics of converbs is analyzed by simply listing all possible interpretations as a disjunction - a less desirable approach from a theoretical point of view).

In this article I argue that Russian converbs have a general temporal meaning - anteriority of PF converbs and simultaneity of IPF converbs. The main focus of the present analysis is thus on the

\footnotetext{
${ }^{1}$ The RuN corpus is a parallel corpus of Russian, Norwegian and English texts, developed on the basis of the Oslo Multilingual Corpus (University of Oslo). All the examples in this article (unless specified otherwise) are taken from Lyudmila Ulitskaya's novel "Medea and her children" and are presented in the following way. The first sentence shows the original Russian sentence (source text - ST) which is followed by a glossing of the matrix clause and the converb clause, and then by an English sentence from an authorized, published translation (target text - TT) of the Russian text.
} 
tense and aspect of the converb construction and the effect of the position of the converb in the sentence (i.e. information structure) on its temporal interpretation.

The paper is organized as follows. Section 2 addresses the interpretational possibilities of Russian converbs. In section 3, I investigate the possibility of attributing the basic meaning of Russian converbs to the temporal interpretation of the converb morphemes, more specifically the contribution of relative tense by the converb morphemes '- $v$ ' and '-(j)a'. Some corpus data is presented in section 4. Section 5 presents possible solutions to the analysis of converbs with a temporal interpretation that is different from what is assumed to be the underlying meaning, in particular, a posteriority interpretation of sentence-final PF converbs. Conclusions are presented in section 6 .

\section{Interpretation of converbs}

According to König $(1995,58)$, "the interpretation of a converb in a specific utterance is the result of an interaction between a basic vague meaning of the converb and a wide variety of syntactic, semantic and contextual factors”. In Russian, the range of possible meanings is somewhat narrower than in many Eurasian languages (Nedjalkov 1995) and is described by Weiss $(1995,250)$ as the 'common European standard'. On the other hand, Russian converbs are claimed to be more semantically diverse and more frequent than in some other Slavic languages (cf. Nedjalkov 1995, 108). Constructions involving converbs can express simultaneity, anteriority, posteriority, cause, concession, manner, instrument, attendant (or accompanying) circumstance, condition, goal, place, explanation and some other meanings. Some examples are in (3) to (5):

Temporal (simultaneity):

$$
\begin{array}{llllll}
\text { Pro-chod-ja } & \text { sovsem } & \text { rjadom } & \text { s } & \text { devočk-ami, oni } & \text { u-vide-l-i, } \\
\text { PF-walk.IPF-CONV } & \text { very } & \text { close } & \text { with } & \text { girl-INS.PL they } & \text { PF-see-PST-PL }
\end{array}
$$

čto razgljadyvajut oni sovsem ne ovec, a kakuju-to nachodku na zemle.

'As they passed close to the girls, they saw that it was not the sheep they were staring at but something they had found on the ground.'

Attendant circumstance:

$(4)$

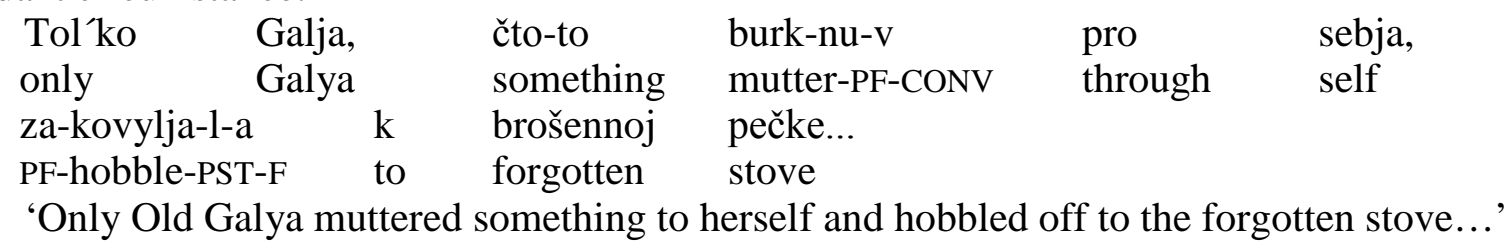

Reason / explanation:

\begin{tabular}{|c|c|c|c|}
\hline $\begin{array}{ll}\text { I } & \text { Medeja } \\
\text { and } & \text { Medea }\end{array}$ & $\begin{array}{l}\text { v-sta-l-a, } \\
\text { PF-stand-PST-F }\end{array}$ & $\begin{array}{l}\text { za-konči-v } \\
\text { PF-finish-CONV }\end{array}$ & $\begin{array}{l}\text { razgovor. } \\
\text { conversation }\end{array}$ \\
\hline
\end{tabular}

It is sometimes difficult to decide which meaning a particular converb has, since one and the same converb can be interpreted as temporal and at the same time express another semantic relation with respect to the matrix event (e.g. means, attendant circumstance, etc.).

As mentioned above (cf. section 1), two ways of analyzing the semantic interpretation of converbs are discussed in the literature: according to the first one, converbs are analyzed in terms of polysemy - i.e. all the different meanings of converbs are linguistically determined, so the meaning of the grammatical category of converb is polysemous (or multiply ambiguous) - e.g. (Boguslavskij 1977; Apresjan 1983). According to the proponents of this approach, a challenging task in the study of semantic interpretation of converbs is to determine the conditions (based on the information from all linguistic levels) for separating the different meanings of a particular CC. The second approach which goes under the terms of underspecificity, or vagueness - holds that all the various meanings of converbs are contextually determined and are variants of one invariant (intermediate) meaning of the converb construction. This view is defended by e.g. Stump (1985) and Kortmann (1991) who 
analyze the English converb, Rappaport (1984) - for the Russian converb, and Halmøy (1982) - for the French converb construction. Proponents of the 'polysemy' approach argue that the full range of utterance meanings associated with converbs cannot be based on one vague meaning ("Gesamtbedeutung”, cf. König $(1995,59)$ ) because this meaning is either too specific to be compatible with all possible interpretations, or too unspecific, too general.

The next section will present a possible semantic analysis of sentences with converbs in Russian according to which the converb morphemes '- $v$ ' and '-(j)a' express the temporal meaning of anteriority (relative past tense) and temporal overlap (relative present tense), respectively. I then discuss whether these temporal meanings can in fact be the basic (vague) meanings of the two converb constructions in Russian.

\section{The basic meaning of Russian converbs}

The temporal calculus presented in this section is based on event semantics (Davidson 1967; Parsons 1990; Eckardt 2002) and the compositional semantic analysis of tense and aspect (Grønn 2003; von Stechow 2009) ${ }^{2}$. In general, there are three temporal objects that are involved in sentences: the event in question, the topic time (TT) (also called the reference time - i.e. the time for which an assertion is made), and the indexical time of utterance (the utterance time, the speech time or the local evaluation time). Tense is typically a relation between the speech time and the topic time, while aspect is a relation between the event time and the topic time (Klein 1994, 1995). The meaning of the Imperfective aspect is that the topic time is included in the event time. The Perfective, on the other hand, means that the event time is included in the topic time, cf. the representation in (6):

$$
\begin{aligned}
& \text { IPF: } \mathrm{t} \subset \mathrm{e} \\
& \text { PF: } \mathrm{e} \subset \mathrm{t}
\end{aligned}
$$

The main assumption is that aspect takes a set of events as input and gives a set of times as output (Kratzer 1998), and that tense further operates on this set of times. Grammatical tense in the matrix clause plays a crucial role in the interpretation of converb sentences, as it interacts with the assumed relative tense of converb constructions. Following von Stechow (2009), I adopt the indefinite semantics of Past (there is at least one time interval in the past where $\mathrm{P}$ is true), i.e. Past is an existential quantifier that shifts the local evaluation time backwards.

As mentioned above, Russian converbs occur in one of the two aspectual forms - Perfective (PF) and Imperfective (IPF). IPF forms are usually formed from the present verb-stem, while PF forms are formed from the past stem. PF converbs are formed by adding the suffix '-v' (or '-vši') to the past verb stem, while IPF converbs are formed by adding '-(j)a' to the present verb stem. The IPF form usually denotes simultaneity with the event in the main clause, while the prototypical interpretation of the PF form in a neutral, sentence-initial position is anteriority with respect to the event of the main clause. Converbs can only express relative tense, i.e. their temporal interpretation depends on the tense of the verb in the main clause (and not on the deictic utterance time) as well as the converb morphology and the aspectual form of the converb construction. I will argue that the relative tense of the Russian converb construction is encoded by the converb morphology (morphemes '-(j)a' and '-v'). However, the converb morphology correlates with the aspectual morphology, since PF converbs are formed with the converb suffix '-v(ři)' and IPF converbs are formed with '-(j)a' ${ }^{3}$. This interdependence can be dealt with descriptively by adding a subcategorization feature for the converb morphemes: $-\mathrm{V}$ [subcat: PF] and -(j)a [subcat: IPF].

In addition to converb constructions that are purely temporal, we find converbs which have other interpretations: attendant circumstance, manner, explanation, result, cause. However, unlike converbs in some other languages with impoverished morphology, Russian CCs always bear some kind of temporal interpretation (due to the distinct converb morphology (morphemes - $\mathrm{v}$ and $-(\mathrm{j}) \mathrm{a}$

\footnotetext{
${ }^{2}$ For a more detailed presentation of the framework and the temporal calculus I refer the reader to my upcoming dissertation (Filiouchkina Krave in progress).

${ }^{3}$ There are some counterexamples (e.g. the PF converb uvidja ('PF.see-Conv') used on a par with uvidev ('PF.seeConv'), but they are few and do not change the main picture.
} 
expressing relative past and present, respectively) and the aspectual morphology encoding the inclusion relation between the topic time and the event time) - also when the basic interpretation is not a purely temporal one. This observation supports the vagueness approach (cf. section 2), i.e. that Russian converbs have a general vague meaning. I return to the question of contextually vs. linguistically determined interpretation in section 4 below, but I will first present a possible compositional analysis for a sentence with a Perfective converb (marked by '-v') in sentence-initial position.

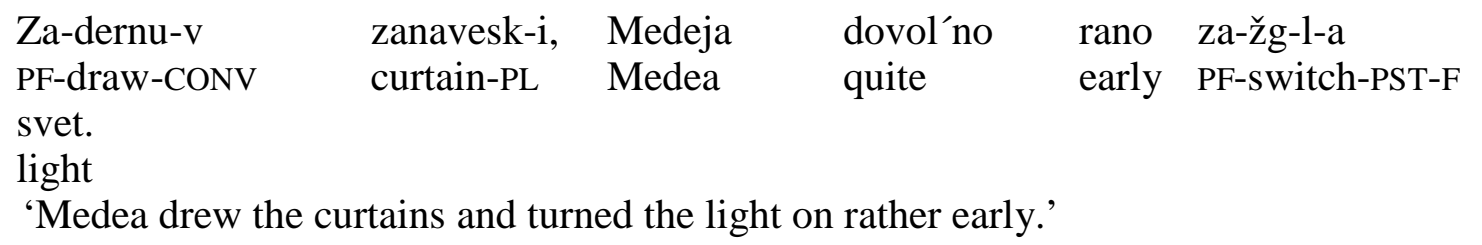

Figure 1: Analysis of (7) - (PF converb)

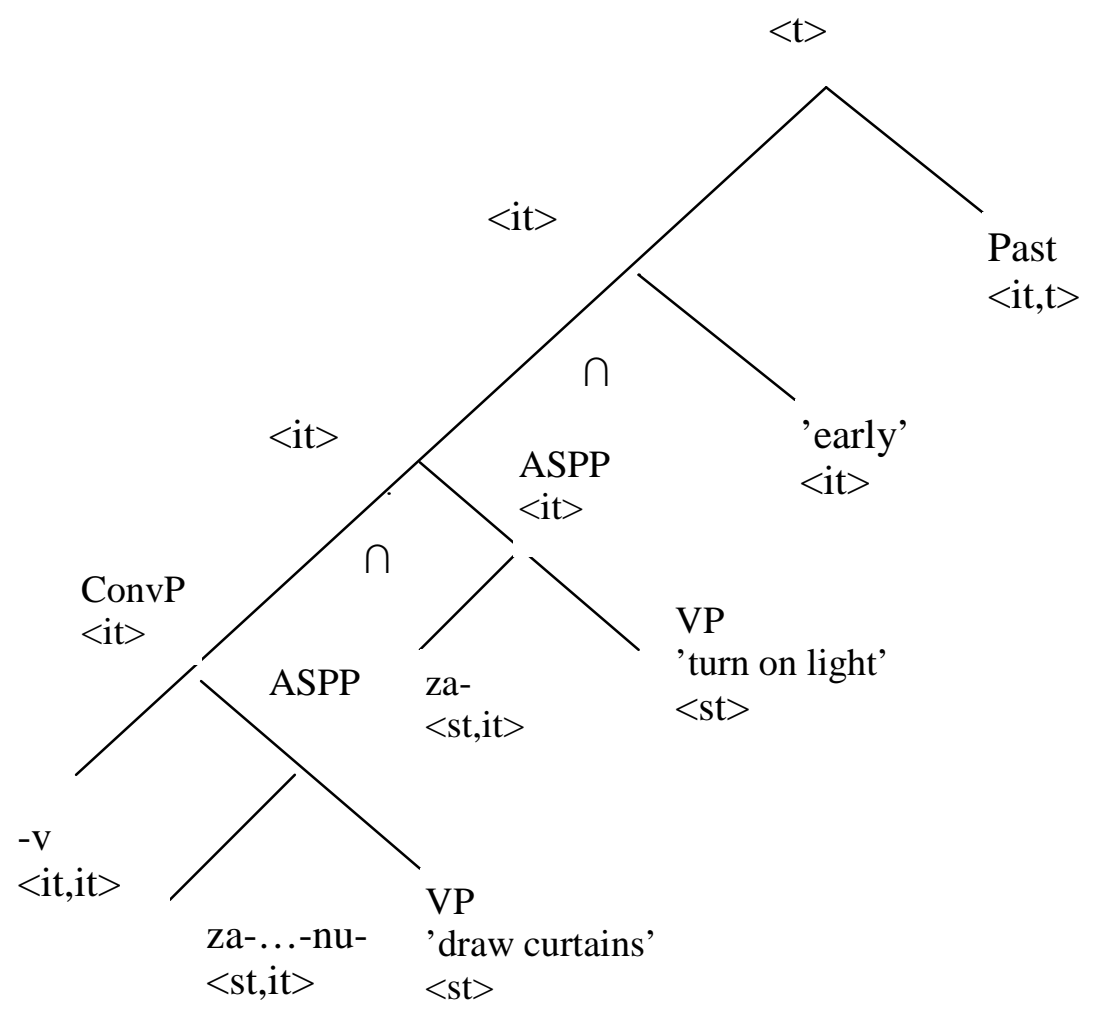

The semantic analysis of (7) is presented in figure 1 . The subject of the sentence is omitted, but is assumed to originate in the matrix VP and have the thematic role of the Agent of the event in question.

In this analysis, two operations are used in the composition: Functional Application (FA) and Predicate Modification (PM) (Heim and Kratzer 1998). The former shifts the semantic type of the expression in question, while the latter does not. Converbs are assumed to be adjuncts from the syntactic point of view. Syntactic adjunction corresponds to intersection ( $\cap$ ) in the semantics (by PM). I assume a bottom-up compositional semantic analysis that makes use of a Lambda calculus and gives a truth value (type $<\mathrm{t}>$ ) at the top (cf. figure 1). The following set of types is used in the analysis:

1. $\mathrm{s}$ is a basic type denoting the type of events.

2. $\mathrm{i}$ is a basic type denoting the type of times.

3. Combinations of basic types such as $<$ a,b $>$ gives a complex type that denotes the type of functions from expressions of type a to expressions of type b. For example, the aspectual 
operator is assumed to have the type $<$ st,it $>-$ i.e. it takes a set of events $(<$ st $>$ ) in the VP as input and gives a set of times $(<\mathrm{it}>$ ) as output. The suffix $-\mathrm{v}$ (the relative past tense marker of the Russian PF converb) is assumed to have the semantic type <it,it $>-$ a function from a set of times $(\lambda \mathrm{T})$ to another set of times $\left(\lambda \mathrm{t}_{1}\right)$ such that there is a time interval $t$ at which $\mathrm{T}$ holds and t precedes $t_{1}$. Hence, relative past is a time shifter.

The Lambda calculus for sentence (7) is given in 1 to 13:

1. -nu- (PF) ${ }^{4} \approx \lambda \mathrm{P} \lambda \mathrm{t} \exists \mathrm{e} . \mathrm{P}(\mathrm{e}) \wedge \mathrm{e} \subset \mathrm{t}$

2. '-der-' (draw curtains) $\approx>\lambda$ e.draw_curtains $(\mathrm{e})$

$1+2=3$ (by FA):

3. ASPP: $\lambda \mathrm{P} \lambda \mathrm{t} \exists \mathrm{e} . \mathrm{P}(\mathrm{e}) \wedge \mathrm{e} \subset \mathrm{t}(\lambda$ e.draw_curtains(e) $)=$ (by $\beta$-reduction)

$=\lambda \mathrm{t} \exists \mathrm{e} . \lambda \mathrm{e}^{\prime}$. draw_curtains( $\left(\mathrm{e}^{\prime}\right)(\mathrm{e}) \wedge \mathrm{e} \subset \mathrm{t}=\lambda \mathrm{t} \exists \mathrm{e}$.draw_curtains $(\mathrm{e}) \wedge \mathrm{e} \subset \mathrm{t}$

4. '- $\mathrm{v}$ ': $\lambda \mathrm{T} \lambda \mathrm{t}_{1} . \exists \mathrm{t} . \mathrm{T}(\mathrm{t}) \wedge \mathrm{t}\left\langle\mathrm{t}_{1}\left(\lambda \mathrm{t}_{1}\right.\right.$ is the set of time intervals which are after the topic time of the VP-event 'draw curtains')

$3+4=5$ (by FA):

5. $\lambda \mathrm{T} \lambda \mathrm{t}_{1} . \exists \mathrm{t} . \mathrm{T}(\mathrm{t}) \wedge \mathrm{t}\left\langle\mathrm{t}_{1}\left(\lambda \mathrm{t}^{\prime} \exists\right.\right.$ e.draw_curtains(e) $\left.\wedge \mathrm{e} \subset \mathrm{t}^{\prime}\right)=$

$=\lambda \mathrm{t}_{1 .} \exists \mathrm{t} .\left(\lambda \mathrm{t}^{\prime} \exists \mathrm{e} . d r a w_{-}\right.$curtains $\left.(\mathrm{e}) \wedge \mathrm{e} \subset \mathrm{t}^{\prime}\right)(\mathrm{t}) \wedge \mathrm{t}<\mathrm{t}_{1}=$

$=\lambda \mathrm{t}_{1} . \exists \mathrm{t} . \exists \mathrm{e} . d r a w_{-}$curtains(e) $\wedge \mathrm{e} \subset \mathrm{t} \wedge \mathrm{t}<\mathrm{t}_{1}$

6. za-(PF in the matrix) $\approx>\lambda \lambda t \exists \operatorname{e} . \mathrm{P}(\mathrm{e}) \wedge \mathrm{e} \subset \mathrm{t}$

7. turn on light $\approx>\lambda$ e.turn_on_light(e)

$6+7=8$ (by FA):

8. ASPP (zažeč svet): $\lambda \mathrm{t} . \exists$ e.turn_on_light(e) $\wedge \mathrm{e} \subset \mathrm{t}$

5+8=9 (by PM):

9. $\lambda \mathrm{t}_{1} . \exists \mathrm{t} . \exists \mathrm{e} . d r a w \_c u r t a i n s(\mathrm{e}) \wedge \mathrm{e} \subset \mathrm{t} \wedge \mathrm{t}<\mathrm{t}_{1} \cap \lambda \mathrm{t}^{\prime} . \exists \mathrm{e}^{\prime}$.turn_on_light(e') $\wedge \mathrm{e}^{\prime} \subset \mathrm{t}^{\prime}=$

$=\lambda \mathrm{t}_{3} . \exists \mathrm{t} . \exists$ e.draw_curtains(e) $\wedge \mathrm{e} \subset \mathrm{t} \wedge \mathrm{t}<\mathrm{t}_{3} \wedge \exists \mathrm{e}^{\prime}$.turn_on_light(e') $\wedge \mathrm{e}^{\prime} \subset \mathrm{t}_{3}=$

$=\lambda \mathrm{t}_{3} . \exists \mathrm{t} . \exists \mathrm{e} . \exists \mathrm{e}^{\prime}$.draw_curtains(e) $\wedge \mathrm{e} \subset \mathrm{t} \wedge \mathrm{t}<\mathrm{t}_{3} \wedge$ turn_on_light(e') $\wedge \mathrm{e}^{\prime} \subset \mathrm{t}_{3}$

10. 'early' $\approx>\lambda t_{2 .}$ early $\left(\mathrm{t}_{2}\right)$

$9+10=11$ (by PM):

11. $\lambda \mathrm{t}_{2 .}$ early( $\left.\mathrm{t}_{2}\right) \cap \lambda \mathrm{t}_{3 .} . \exists \mathrm{t} . \exists \mathrm{e} . \exists \mathrm{e}^{\prime}$.draw_curtains(e) $\wedge \mathrm{e} \subset \mathrm{t} \wedge \mathrm{t}<\mathrm{t}_{3} \wedge$ turn_on_light(e')

$\wedge \mathrm{e}{ }^{\prime} \subset \mathrm{t}_{3}=\lambda \mathrm{t}_{4} . \exists \mathrm{t} . \exists \mathrm{e} . \exists \mathrm{e}^{\prime}$.draw_curtains(e) $\wedge \mathrm{e} \subset \mathrm{t} \wedge \mathrm{t}\left\langle\mathrm{t}_{4} \wedge\right.$ turn_on_light(e') $\wedge$ e' $\subset \mathrm{t}_{4} \wedge$ $\operatorname{early}\left(\mathrm{t}_{4}\right)$

12. Past $\approx>\lambda \mathrm{T} . \exists \mathrm{t} . \mathrm{T}(\mathrm{t}) \wedge \mathrm{t}<\mathrm{t}_{0}\left(\mathrm{t}_{0}=\right.$ utterance time $)$

$11+12=13$ (by FA):

13. $\lambda \mathrm{T} . \exists \mathrm{t} . \mathrm{T}(\mathrm{t}) \wedge \mathrm{t}<\mathrm{t}_{0}$

$\left(\lambda \mathrm{t}_{4} . \exists \mathrm{t}\right.$ '. $\exists \mathrm{e} . \exists \mathrm{e}^{\prime}$. draw_curtains(e) $\wedge \mathrm{e} \subset \mathrm{t}^{\prime} \wedge \mathrm{t}^{\prime}<\mathrm{t}_{4} \wedge$ turn_on_light(e') $\wedge \mathrm{e}^{\prime} \subset \mathrm{t}_{4} \wedge$ early(t $\left.\left.\mathrm{t}_{4}\right)\right)$ $=\exists \mathrm{t}\left(\lambda \mathrm{t}_{4} . \exists \mathrm{t}^{\prime} . \exists \mathrm{e} . \exists \mathrm{e}^{\prime} . \operatorname{draw} \_\right.$curtains(e) $\wedge \mathrm{e} \subset \mathrm{t}^{\prime} \wedge \mathrm{t}^{\prime}<\mathrm{t}_{4} \wedge$ turn_on_light(e') $\wedge \mathrm{e}^{\prime} \subset \mathrm{t}_{4} \wedge$ early(t $\left.\left.\mathrm{t}_{4}\right)\right)(\mathrm{t}) \wedge \mathrm{t}<\mathrm{t}_{0}=\exists \mathrm{t} . \exists \mathrm{t}$ '. $\exists \mathrm{e} . \exists \mathrm{e}^{\prime} . d r a w \_c u r t a i n s(\mathrm{e}) \wedge \mathrm{e} \subset \mathrm{t}^{\prime} \wedge \mathrm{t}^{\prime}<\mathrm{t} \wedge$ turn_on_light(e') $\wedge$ $\mathrm{e}^{\prime} \subset \mathrm{t} \wedge \operatorname{early}(\mathrm{t}) \wedge \mathrm{t}<\mathrm{t}_{0}$

The Lambda calculus presented in 1 to 13 should be read as follows. The VP 'draw curtains', an event predicate, is input for the PF operators denoted by 'za-' and '-nu-' and by FA we get a set of

\footnotetext{
${ }^{4}$ For simplicity, I gloss over the fact that we have two PF morphemes in the converb in (7): i.e. the prefix 'za-' and the suffix '-nu-'.
} 
times in the ASPP ('zadernut' zanaveski'). The semantic contribution of PF is that the topic time includes the event time. Then by means of FA the converb suffix '- $v$ ' - a time shifter - takes the set of times (in the ASPP) as input and returns a set of times $t_{1}$ as output. The temporal meaning of the morpheme '-v' (anteriority) gives us the set of time intervals which follow the topic time of the converb event.

The aspectual phrase 'zažeč' svet' ('turn on the light (PF)') in the matrix clause is also a set of times, i.e. the result of combining the PF prefix 'za-' with the VP by Functional Application. By intersection (between the two time intervals - one denoted by the converb phrase 'zadernuv zanaveski' and the other one by the aspectual phrase 'zažeč' svet'), we get a new set of times (cf. step 9). Again by intersection, the set of times obtained in 9 combines with another set of time intervals denoted by the temporal adverbial 'early', which again gives a new set of time intervals (step 11). Both the adverb and the converb construction are assumed to be adjuncts, i.e. they can be freely added or removed from the main sentence without changing its basic syntactic structure. Finally, the (deictic) past tense operator (expressed by the suffix '-l-') takes as input the set of times we obtained by the operations so far and returns (by FA) a truth value.

According to this analysis, the converb clause always modifies the topic time for the main clause, disregarding its position in the sentence. The meaning attributed to the converb suffix '- $\mathrm{v}$ ' is that of temporal anteriority $\left(\mathrm{t}<\mathrm{t}_{1}\right)$. The data analysis presented in section 4 will show that initial PF converbs always express anteriority, while PF converbs in the position following the matrix clause are often interpreted in terms of anteriority but may also receive simultaneity and posteriority readings. I return to this issue in the data analysis in 4 and try to account for a posteriority interpretation of PF converbs in section 5.

Sentences with Imperfective converbs can be analyzed in a similar way to that demonstrated for Perfective converb sentences. The suffix '-(j)a' (in addition to a subcategorization feature [subcat: IPF]) has a weak semantics and is assumed to express temporal overlap of some kind with the topic time of the matrix clause. The suffix has the meaning given in (8):

'-(j)a': $\lambda \mathrm{T} \lambda \mathrm{t}_{1 .} \exists \mathrm{t} . \mathrm{T}(\mathrm{t}) \wedge \mathrm{tot}_{1}\left(\lambda \mathrm{t}_{1}\right.$ is the set of time intervals which overlap with the topic time of the VP-event denoted by the converb construction).

I will now examine a sample of sentences with PF and IPF converbs in the RuN corpus to see if the analysis provided here can be applied to all instances of converbs occurring in different positions in the sentence.

\section{Analysis of the Russian corpus data}

Table 1 shows occurrences of sentences with PF and IPF converbs in different positions in the sentence and their interpretations - purely temporal $(T)$ vs. other interpretations. The data set includes a total of 151 sentences with converbs in the PF form and 226 sentences with converbs in the IPF form. The top row shows the position of the CC in the sentence. There are six positions that can be occupied by a converb clause: sentence-initial, sentence-initial after an adverbial, sentencefinal and three sentence-medial positions $(1$ - between the subject and the main predicate, 2 preceding the clause it modifies, 3 - following the clause it modifies). Temporally interpreted converbs are in bold; other interpretations include manner, attendant circumstance, explanation, cause, result, etc. As was already pointed out, when a converb construction has a different basic meaning than the purely temporal one, it is still compatible with a temporal interpretation. If the data presented below is compatible with the semantics attributed to PF and IPF converbs in section 3 , it will be possible to conclude that Russian converbs should be analyzed in terms of vagueness and not polysemy.

Table 1: Temporal meaning and other interpretations of Russian converbs in "Medea and her children” by L. Ulitskaya 


\begin{tabular}{|c|c|c|c|c|c|c|c|c|c|c|c|c|}
\hline Position & \multicolumn{2}{|c|}{$\begin{array}{l}\text { Sentence- } \\
\text { initial }\end{array}$} & \multicolumn{2}{|c|}{$\begin{array}{l}\text { Sentence- } \\
\text { initial after } \\
\text { an } \\
\text { adverbial }\end{array}$} & \multicolumn{2}{|c|}{$\begin{array}{l}\text { Sentence- } \\
\text { final }\end{array}$} & \multicolumn{2}{|c|}{$\begin{array}{l}\text { Medial-1, } \\
\mathrm{CC} \text { b/w } \\
\text { subject and } \\
\text { main } \\
\text { predicate }\end{array}$} & \multicolumn{2}{|c|}{$\begin{array}{l}\text { Medial-2, } \\
\text { CC } \\
\text { precedes } \\
\text { the clause } \\
\text { it modifies }\end{array}$} & \multicolumn{2}{|c|}{$\begin{array}{l}\text { Medial-3, } \\
\text { CC } \\
\text { follows } \\
\text { the clause } \\
\text { it modifies }\end{array}$} \\
\hline Interpretation & $\mathrm{T}$ & other & $\mathrm{T}$ & other & $\mathrm{T}$ & other & $\mathrm{T}$ & other & $\mathrm{T}$ & other & $\mathrm{T}$ & other \\
\hline $\begin{array}{l}\text { PF-CC } \\
\text { Total: } 151\end{array}$ & 15 & 18 & 6 & 4 & 2 & 28 & 11 & 18 & 14 & 15 & 3 & 17 \\
\hline $\begin{array}{l}\text { IPF-CC } \\
\text { Total: } 226\end{array}$ & 13 & 16 & 4 & 2 & 5 & 73 & 2 & 26 & 4 & 18 & 6 & 57 \\
\hline
\end{tabular}

As shown above, converb constructions can have a temporal interpretation in all six positions, although some quantitative differences can be observed: e.g. in the sentence-initial position and in the medial position where the CC precedes the main clause, converbs occur with a temporal meaning approximately as often as with other (non-temporal) interpretations, whereas sentencefinal CCs and sentence-medial CCs which follow the clause they modify (usually the main clause) are rarely interpreted as purely temporal.

To see which temporal interpretations occur with converbs in the different positions, the temporally interpreted converbs are shown separately in table 2. In addition, if no clearly temporal relation was found (as in the case of overlap and posteriority of PF converbs), occurrences of sentences with non-temporal converbs which are compatible with one or another temporal relation are given in parentheses.

Table 2: Temporal reference of Russian converb constructions

\begin{tabular}{|l|l|l|l|}
\hline & Anteriority & Overlap & Posteriority \\
\hline -v converbs (PF): & & & \\
initial & 15 & - & - \\
after adverbial & 6 & - & - \\
final & 2 & $-(26)^{5}$ & $-(2)^{7}$ \\
medial 1 & 11 & - & - \\
medial 2 & 14 & - & - \\
medial 3 & 3 & $-(4)^{6}$ & - \\
\hline -(j)a converbs (IPF): & & & \\
initial & n/a & 13 & n/a \\
after adverbial & & 4 & \\
final & & 5 & \\
medial 1 & & 2 & \\
medial 2 & & 4 & \\
medial 3 & & 6 & \\
\hline
\end{tabular}

As shown in table 2, PF CCs may have different temporal interpretations (anteriority, simultaneity, and posteriority) - anteriority is obligatory in sentence-initial position (cf. (7) above) as well as in preverbal sentence-medial positions. Anteriority in postverbal sentence-medial (cf. (9)) and final positions is less frequent.

$\begin{array}{llllll}\text { ”Nado } & \text { by } & \text { navestit } & \text { Nin-u”(..) } & \text { po-duma-l-a } & \text { Medeja, } \\ \text { need } & {[\text { by] }} & \text { visit.INF } & \text { Nina-ACC } & \text { PF-think-PST-F } & \text { Medea, }\end{array}$

\footnotetext{
${ }^{5}$ Cf. example (10) below, with a non-temporal converb expressing attendant circumstance, with the temporal overlap relation inferred from the meanings of the converb event and the matrix event.

${ }^{6}$ Cf. example (11) below, where the converb promenjav ('PF-swap-CONV') expresses an attendant circumstance, and is thus compatible with temporal overlap with respect to the matrix event.

${ }^{7}$ The converb constructions in (13) and (14) below are interpreted in terms of posteriority due to contextual factors, but the core meaning of the converb clause in both cases is elaboration of the matrix clause event.
} 
vs-pomni-v o prežn-ej feodosijsk-oj sosedk-e...

PF-remember-CONV about former-PREP Theodosia-PREP.ATTR neighbour-PREP

'”I really ought to visit Nina”, Medea thought (...), remembering her former Theodosia neighbor...'

In (9), the anteriority interpretation comes from the converb suffix '-v' (cf. section 3), and the resultant state of the converb event (vspomniv 'PF-remember-CONV') overlaps with the matrix event of thinking.

PF converbs in our data do not express simultaneity as such. Nevertheless, temporal overlap of PF converbs occurring in postverbal positions (sentence-final or sentence-medial positions following the modified verb) can be inferred in sentences where converbs express attendant circumstance (AC), manner, reason or explanation, cf. (10) with a converb expressing AC (and (5) above with a converb expressing a reason or an explanation for the matrix clause event):

\begin{tabular}{|c|c|c|c|c|c|}
\hline $\begin{array}{l}\text {...Aleksej } \\
\text { Aleksey } \\
\text { beremenn-oj. } \\
\text { pregnant-INS. }\end{array}$ & $\begin{array}{l}\text { Kirillovič } \\
\text { Kirillovich } \\
\text {.. } \\
\text { ATTR }\end{array}$ & $\begin{array}{l}\text { u-echa-l, } \\
\text { PF-leave-PST }\end{array}$ & $\begin{array}{l}o \text {-stavi-v } \\
\text { PF-leave-CONV }\end{array}$ & $\begin{array}{l}\text { ee } \\
\text { her }\end{array}$ & $\begin{array}{l}\text { opredelenno } \\
\text { definitely }\end{array}$ \\
\hline
\end{tabular}

The inferred simultaneity interpretation in (10) and (5) is due to an identity relation between the events in the matrix and the converb clauses: i.e. the event of going back to Moscow in (10) is identical to (in this context) the event of leaving someone, and the event of standing up in (5) corresponds (in this particular context) to the ending of the conversation. Also in (11) the PF converb in sentence-medial position is compatible with temporal overlap:

\begin{tabular}{lllll}
...a & kogda & brosi-l-a & režisser-a, & \multicolumn{2}{l}{ pro-menja- $v$} \\
and & when & leave.PF-PST-F & producer-ACC & \multicolumn{2}{l}{ PF-exchange-CONV } \\
ego na fizika, dolgo eščo & prodolža-l-a & taska-t' ${ }^{\prime}$ mal'čik-a \\
him for physicist-ACC long still & continue-PST-F & drag.IPF-INF boy-ACC \\
za sob-oj. & & & & \\
after & self-INS & & &
\end{tabular}

'....and when she swapped the producer for a physicist, she continued dragging the boy around with her for many years.'

Note that in (11) the converb clause modifies the preceding 'when' clause (the converb event overlaps with the event expressed by the finite verb in the 'when' clause), not the matrix clause of the sentence. This structure is lost in the English translation, where only the converb event is mentioned in the 'when' clause.

Consider also (12), where both the anteriority and the simultaneity readings seem to be possible:
Vernu-l-sja
on $\mathrm{V}$
Rastorguevo, pribavi-v
sem'
returned.PF-PST-REFL he in Rastorguevo put.on.PF-CONV seven
killogramm-ov ves-u i tri santimetra rostu...
kilogram-GEN.PL weight-GEN
'He returned to Rastorguevo, having put on seven kilograms in weight and three centimeters in height...'

In (12), the converb clause denotes a change of physical state (weight and height) of the agent of the matrix event. The change itself is compatible with anteriority: gaining more weight and growing higher precedes the event of returning (the semantics of ' $-\mathrm{v}$ '). Accordingly, the resultant state (being seven kilograms heavier and three centimeters taller) must temporally overlap with the returning event. In deciding between simultaneity and anteriority readings we must carefully distinguish 
between the event proper and the resultant state. The formalization presented in section 3 above (and section 5 below) is strictly speaking concerned with the topic times associated with the event itself.

Some PF converbs occurring in sentence-final positions are compatible with posteriority (examples (13) and (14)).

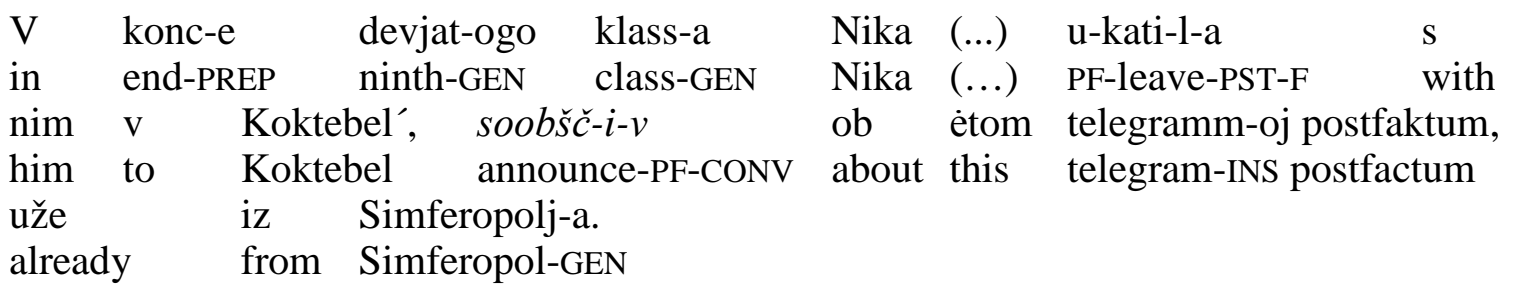

'At the end of the ninth grade Nike (...) flounced off with him to Koktebel, announcing this ex post facto by telegram when she was already in Simferopol.'

\begin{tabular}{llllll} 
Po nočam, & leža $(\ldots)$ oni & ve-l-i & \multicolumn{2}{l}{ dolgie soderžatel'nye } \\
at nights & lie.IPF.Conv they & pursue-PST-PL & long meaningful \\
razgovory, & so-chrani-v & s tech por na vju žizn' \\
conversations & PF-keep-CONV & from those times for all life
\end{tabular}

glubokoe čuvstvo...

deep feeling

'At night, lying (...) they engaged in long, deeply meaningful conversations and retained from that time for the whole of the rest of their lives a deep emotional bond...'

In both (13) and (14) the co-text is responsible for the posteriority reading - in particular, the presence of temporal phrases corresponding to the English clause "when she was already in Simferopol" and the temporal expression "from that time for the whole of the rest of their lives".

The analysis of corpus data suggests that the temporal interpretation of PF converb constructions is partly dependent on their position in the sentence. Sentence-initial converbs are always interpreted as preceding the main clause event, whereas in sentence-final and sentencemedial positions, where the converb construction comes after the clause it modifies, the converb event may temporally overlap with, precede or follow its host event.

PF converbs are not used with a clear posteriority meaning in our data (as opposed to the use of PF converbs to specifically express the anteriority relation between the converb event and the matrix event), but a posteriority interpretation is possible provided the appropriate context (as in (13) and (14) above). The choice between overlap (simultaneity) and anteriority seems to depend on the Aktionsart (lexical semantics) of the converb construction - i.e. with semelfactives overlap is the most common interpretation (On skazal, vzdrognuv - 'He said shuddering (PF)'). With accomplishments, on the other hand, we usually get the meaning of anteriority - e.g. On zasnul, dočitav knigu - 'He fell asleep, having read (finished reading) the book'. The temporal interpretation clearly depends on the degree of event integration (cf. Fabricius-Hansen and Haug forthcoming). For example, the shuddering event describes the manner of the speaking event, while the event of falling asleep is perceived as less integrated into the event of reading.

In the data-set analyzed here, Imperfective converbs with a temporal meaning are all interpreted as simultaneous with the topic time of the clause they modify. As shown in table 2, such converbs are found in all positions in the sentence. An example of an IPF converb construction which has a temporal interpretation in sentence-initial position is given in (15), while (16) is an instance of an IPF converb occurring in sentence-final position.

$\begin{array}{llllll}\text { Prochodj-a } & \text { sovsem } & \text { rjadom } & \text { s } & \text { devočk-ami, oni u-vide-l-i, čto } \\ \text { walk.IPF-CONV } & \text { very } & \text { close } & \text { with girl-INS.PL they } & \text { PF.see-PST-PL }\end{array}$
razgljadyvajut oni sovsem ne ovec, a kakuju-to nachodku na zemle.

'As they passed close to the girls, they saw that it was not the sheep they were staring at but something they had found on the ground.' 
Also in the case of IPF converb constructions Aktionsart plays an important role. For instance, sentence-initial IPF converbs are often interpreted as temporal if they belong to the aspectual classes of activities or accomplishments (cf. example (15) above), although some activity converbs may also express concession (as in (17) below with the converb rugaj-a ('curse.IPF-CONV') used with a habitual interpretation) and quite typically accompanying circumstance - both compatible with the overlap relation. Stative converbs often express a causal relation with respect to their host event. ${ }^{8}$ Also in these cases, the overlap relation between the converb event and the matrix event is preserved - cf. (18):

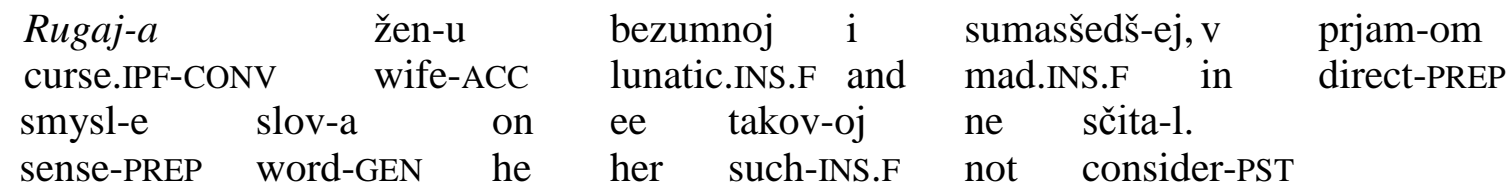

'Cursing her for a lunatic and a madwoman, he did not consider her to be either of those things in a literal sense.'

$\begin{array}{lllllll}\text { Vidj-a nezaurjadnye darovanija } & \text { nov-ogo } & \text { učenik-a, on } & \text { uže } \\ \text { see.IPF-CONV exceptional } & \text { gifts } & \text { new-GEN.M pupil-GEN.M he } & \text { already } \\ \text { po-dum-yva-l } & \text { o } & \text { tom, kak } & \text { by opredeli-t' } & \text { ego } & \\ \text { PF-think-IPF-PST } & \text { about } & \text { that how } & \text { [by] introduce.PF-INF } & \text { him } & \\ \text { so vremen-em } & \text { v } & \text { trupp-u } & \text { vozdušn-ych gymnast-ov... } & \\ \text { with time-INS } & \text { in } & \text { troupe-ACC } & \text { aerial-GEN.PL gymnast-GEN.PL } & \end{array}$

'Seeing the exceptional gifts of his new pupil, he was already considering the possibility of eventually incorporating him into the troupe of aerial gymnasts...'

Sentence-final IPF converbs are typically interpreted as expressing attendant circumstance, manner, cause, means, and explanation. However, a few examples of temporally interpreted IPF converbs in sentence-final position are also found in the data.

In the analysis proposed in section 3, a specific temporal interpretation is assumed to be the underlying meaning of Russian converbs in general: all PF converbs express anteriority with respect to the clause they modify, whereas IPF converbs indicate the relation of temporal overlap. The dataset examined so far is consistent with IPF converbs interpreted as having a temporal overlap of some kind with the topic time of the clause they modify. However, some linguists claim that IPF converbs may in certain contexts be interpreted as contributing a different temporal relation with respect to the matrix clause event. For example, Boguslavskij (1977) cites the following example where the IPF converb 'rabotaja' ('work.IPF.Conv') allegedly has an anteriority reading:

$\begin{array}{lllll}\text { Vsju } & \text { zimu } & \text { rabotaj-a } & \text { bez } & \text { vychodn-ych, on za-konči-l } \\ \text { all } & \text { winter } & \text { work.IPF.CONV } & \text { without } & \text { days.off-GEN he PF-finish-PST } \\ \text { knig-u } & \mathrm{V} \quad \text { konc-e } & \text { vesn-y. } & \\ \text { book-ACC } \quad \text { in } \quad \text { end-PREP } & \text { spring-GEN } & \end{array}$

'Having worked the entire winter without a day off, he finished the book at the end of spring.' (Boguslavskij 1977, 273)

In (19), the anteriority interpretation - contributed by the temporal adverbials in the main clause and

\footnotetext{
${ }^{8}$ See also Apresjan (1983).
} 
the converb clause - overrides the default meaning of simultaneity. Instead, the interpretation we get is that the converb clause provides a kind of background for the main clause event. Note that the most natural form of converb to be used in (19) is the PF converb construction 'prorabotav' (PFwork-Conv) - a perdurative converb in terms of Zaliznyak and Šmelev (2000). However, since the presence of the two temporal adverbials ('the entire winter' and 'at the end of spring', respectively) leaves no doubt about the 'anteriority' relation between the two events, the use of an IPF converb form is permitted. Arguably, the converb clause rabotaja vsju zimu bez vychodnych ('work.IPF.CONV the.whole.winter without days.off') has an interpretation that reminds of a factual IPF reading (Vy kogda-nibud' rabotali vsju zimu bez vychodnych? 'Have you ever worked the whole winter without any days off?') To explain the anteriority relation in (19), we assume that (i) '-(j)a' encodes here the most trivial overlap relation - the identity function $\lambda \mathrm{T} \lambda \mathrm{t}$.T(t) (that is to say, that it has a zero semantics in this case); (ii) IPF is pragmatically strengthened to the relation $\mathrm{e} \subset \mathrm{t}$ (i.e. the factual IPF reading, e.g. (Grønn 2003)), hence we end up with $\mathrm{e} 1 \subset \mathrm{t}$ and $\mathrm{e} 2 \subset \mathrm{t}$ (the matrix event and the converb event share the topic time /are included in one and the same topic time, but the relation between e1 and e2 is underspecified); (iii) there is a pragmatically strengthened relation $\mathrm{e} 1<\mathrm{e} 2$ which is due to the presence of the temporal adverbials "the entire winter" in the converb clause and "at the end of spring" in the matrix clause.

As for PF converbs, the data analyzed so far suggests that all sentence-initial converbs are compatible with an anteriority reading (cf. table 2). However, Rappaport (1984) cites an example of a PF converb in initial position which he claims to have a simultaneity interpretation:

\begin{tabular}{|c|c|c|c|c|c|}
\hline $\begin{array}{l}\text { Vstretj-a } \\
\text { meet.PF-CONV }\end{array}$ & $\begin{array}{ll}\text { vas, } & \text { ja } \\
\text { you } & \text { I }\end{array}$ & $\begin{array}{l}\text { (pri ètom) } \\
\text { (at this) }\end{array}$ & $\begin{array}{l}\text { ne } \\
\text { not }\end{array}$ & $\begin{array}{l}\text { poveril } \\
\text { believed }\end{array}$ & $\begin{array}{l}\text { svoim glazam. } \\
\text { my eyes }\end{array}$ \\
\hline
\end{tabular}

Arguably, the impression of temporal overlap between the two events in (20) is due to the lexical meaning of the main predicate - the event of 'not believing one's eyes' can be understood as a state of being surprised. The simultaneity is only apparent in this sentence. In fact, the situation described requires that a 'meeting' event expressed by the achievement converb construction (vstretj- $a$ 'meet.PF-CONV') has occurred prior to the main clause event. The state of being surprised is in fact a logical consequence of the 'meeting' event, so that the temporal interpretation of the converb construction is not simultaneity but anteriority with an overlap relation between the consequent state of the converb event and the main clause event.

Thus it is still possible to conclude that the temporal interpretation of PF converbs in sentence-initial position is consistent with the analysis presented in section 3. On the other hand, as shown in table 2, our analysis does not explain the possibility of different temporal relations encoded by PF converbs in sentence-final and sentence-medial positions. It is possible to find counterexamples to the anteriority reading of the PF converb constructions (cf. examples (13) and (14)). Obviously, there is a clear dependence of the temporal interpretation on the position of the PF converb construction in the sentence: sentence-initial converb constructions are never interpreted as posterior, whereas sentence-final converbs may be interpreted as anterior, simultaneous, or posterior with respect to the main clause event. In the next section possible solutions to the posteriority interpretation of the PF converb in sentence (13) are proposed with the purpose to find out whether it is possible to preserve the unified account of the semantics of ' $-\mathrm{v}$ ' proposed in section 3 and in that way provide support for the vagueness approach to the interpretation of Russian converbs.

\section{Alternative temporal accounts of PF converbs}

An alternative analysis of the posteriority interpretation of sentence-final converbs (example (13)) can be proposed if we assume that the two clauses - the main clause and the subsequent converb clause - are two coordinate clauses connected by some kind of covert 'conjunction'. In this case, the Past tense of both clauses is deictic - both the topic time of the main clause and the topic time of the converb clause precedes the speech time, but the ordering of the two events is not specified in the semantics. The temporal relation of succession can then be explained in terms of the principle of narrative discourse - i.e. if there are two events expressed by PF (past) verb forms, their temporal 
interpretation follows the linear order (provided there are no other factors that direct the interpretation otherwise). The drawback of this approach to the temporal interpretation of sentences with PF converbs is that it treats the non-finite converb construction as if it were finite.

Another simple strategy would be to assume that the initial matrix expresses relative tense, while the PF converb in postverbal positions has deictic tense (before $\mathrm{t}_{0}$ ). This is problematic because we do not want to say that non-finite adjuncts instantiate the 'main' tense of the sentence. Hence, this approach is in a way similar to the 'coordination' analysis, where both the adjunct and the finite matrix are treated as finite. Moreover, this strategy turns out to be problematic when applied to sentences with a matrix clause with a future time reference. A hypothetical example is constructed in (21):

On vy-jd-et, $\quad$ chlop-nu-v $\quad$ dver'-ju.
he out(PF)-go-3PRS slam-PF-CONV door-INS
'He will go out, slamming the door (behind him).'

Sentence (21) is ambiguous with respect to the temporal interpretation of the converb construction, which may either be read as expressing anteriority or posteriority with respect to the matrix clause event. The second reading (posteriority) cannot be accounted for by the proposed approach, since the converb suffix ' $-\mathrm{v}$ ' does not encode the precedence relation $t<t_{0}$ (deictic past) in this case. The future tense of the matrix clause provides a new reference point for the converb event, which is after the speech time.

Below I propose three other possible solutions and discuss their drawbacks and merits. I start off with the same basic semantics for '-v' as postulated above (cf. section 3, repeated here in (22)).

$$
\mathrm{c}^{\varsigma} \approx \lambda \mathrm{T} . \lambda \mathrm{t}_{1} \cdot \exists \mathrm{t} . \mathrm{T}(\mathrm{t}) \wedge \mathrm{t}<\mathrm{t}_{1}
$$

On this analysis ' $-\mathrm{v}$ ' expresses the strong semantics of anteriority and has the subcategorization feature $-\mathrm{V}$ [subcat: $\mathrm{PF}$ ( (see above). As we saw, this semantics works fine for preverbal PF converbs, as they are all compatible with anteriority. As for overlap and posteriority interpretations of postverbal converb constructions in our data, several strategies can be considered.

Solution 1. On this solution the unified account has to be given up, and it is assumed that '$v^{\prime}$ in postverbal positions has a zero semantics, the identity function $\lambda \mathrm{T} \lambda \mathrm{t}$.T(t), i.e. it is used with PF converbs only for morpho-syntactic reasons (the subcategorization feature). The result of this is the same as above with the factual IPF converb with '-(j)a' (cf. section 4) - i.e. e1 $\subset \mathrm{t}$ and e2 $\subset \mathrm{t}$ and $\mathrm{t}<\mathrm{t}_{0}$ (there is one topic time for both events, and $\mathrm{t}$ precedes the speech time $\mathrm{t}_{0}$ ). But this does not work for sentence (13) repeated here as (23):

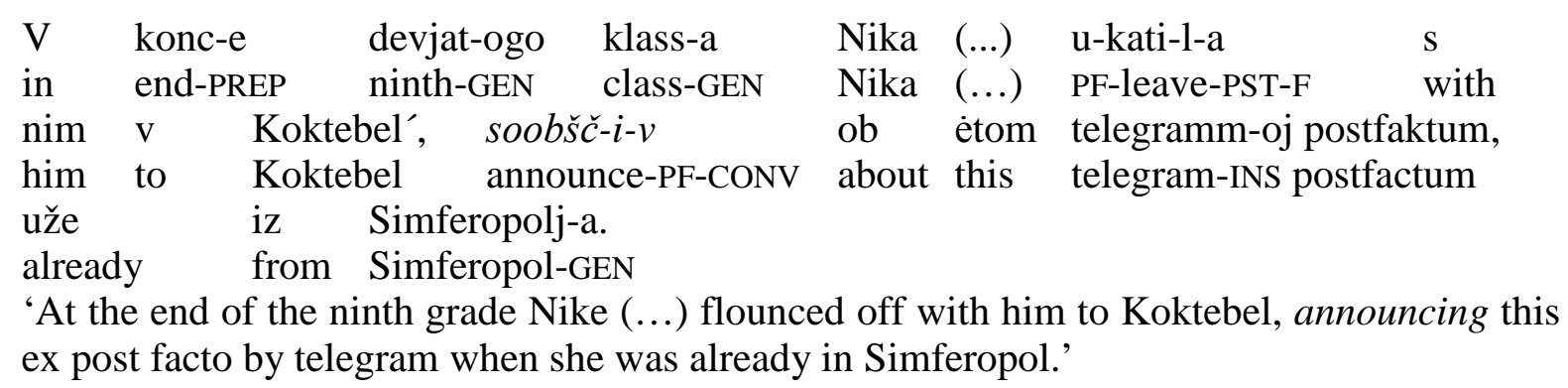

Because of the presence of the temporal expression "postfaktum" and the adverbial phrase "uže iz Simferopolja" that corresponds to the 'when' clause in the English translation ("when she was already in Simferopol"), there are two distinct topic times for the matrix event and the converb event. So it is impossible to assume that these events share one and the same topic time. In fact, the word "postfaktum" in the converb clause signals that the event of announcing is a future event with respect to the matrix event of flouncing off. Due to impoverished morphology this future interpretation cannot be expressed overtly. However, we may argue for the insertion of a covert future operator at LF (von Stechow 2005; Grønn and von Stechow 2010). Sentence (23) is 
interpreted as (24):

(24) Nike flounced off to Koktebel, [will] having announced ('announce-PF-CONV') this post facto...

The insertion of a covert Future in the converb clause is comparable to a covert Future inserted at LF in English sentences with modal verbs (von Stechow 2005); cf. a constructed sentence (25):

\section{You may [will] relax today and [will] write up the article tomorrow.}

English modal verbs have a subcategorization feature [+INF] (i.e. they combine with an infinitival form of the verb), but there are no future forms of infinitives in English.

On this approach, it is possible to keep the same syntax-semantics for (24) as for sentence (7) in section 3 by left-dislocating the converb clause at LF (see figure 1 above). This means that the converb modifies the topic time of the matrix. Since a zero semantics for ' $-\mathrm{v}$ ' is assumed in this sentence, the result of combining it with the ASPP 'announce-PF' is identical to that in the ASPP (i.e. a set of times $t$ such that there is an event $e$ and $e$ is included in $t$ ). Due to the co-text ("postfaktum") and partly the position of the converb in the surface syntax, we insert a covert relative Future (FUT $\left.\approx \lambda T \cdot \lambda t_{1} \cdot \exists t_{2} \cdot T\left(t_{2}\right) \wedge t_{2}>t_{1}\right)$. This Future operator combines by FA with the set of times obtained by the previous operations and gives a set of times $t_{1}$ such that there is a future time $t_{2}$ that is after $t_{1}$ and the event of announcing is included in $t_{2}$. Then the set of times $t_{1}$ is intersected with the set of times $t_{3}$ containing an event of flouncing off. The result of this intersection is a set of times $t_{4}$ such that there is a future time $t_{2}$ which is after $t_{4}$ and which includes the announcing event $e$, and the flouncing off event $e_{1}$ is included in $t_{4}$. Finally, the Past tense operator locates $t_{4}$ before the speech time $t_{0}$. We get the correct result, the posteriority reading of the converb clause event: the topic time of the matrix event (flouncing off) is before the topic time of the converb event (announcing) and the topic time of the matrix is located in the past.

Another positive outcome of adopting a zero semantics for ' $-\mathrm{v}$ ' and the insertion of a covert Future is that a similar analysis can also account for the posteriority of sentence-final PF converbs in future contexts. Recall example (21) above with the future tense in the matrix clause. If we use the proposed solution for the analysis of (21), we get the same temporal relation between the topic times of the matrix event and the converb event (posteriority), with the only difference (compared to the analysis of (23)) that both topic times are located in the future, i.e. after $t_{0}$. The drawback of this solution is that we have to give up the unified semantics for '- $v$ ' (i.e. the expression of relative past) for both anteriority and posteriority readings. But there are alternative solutions.

Solution 2 assumes a covert future operator (as in the first solution) but preserves the unified account of '- $v$ ' (as a past time shifter, cf. the denotation in (22) above). I assume the same syntaxsemantics as above (cf. figure 1) - i.e. the converb clause modifies the topic time of the matrix clause even though it occurs in right-dislocated position in the surface structure. At the level of ConvP we get a set of times $t_{1}$ such that (due to '- $v$ ') there is a past time $t_{2}\left(t_{2}\right.$ precedes $t_{1}$ ) containing an event of announcing. Due to the co-text ("postfaktum"), we insert a relative Future and get a set of times $t_{4}$ such that there is a future time $t_{1}\left(t_{1}\right.$ follows $\left.t_{4}\right)$ such that there is a past time $t_{2}\left(t_{2}\right.$ precedes $\left.t_{1}\right)$ containing an event of announcing. The set of times $t_{4}$ is intersected with the set of times $t_{3}$ containing an event of flouncing off. The result of this intersection is then input to the past tense operator. The result of this is a past time $t\left(t\right.$ precedes $\left.t_{0}\right)$ containing an event of flouncing off (the matrix event), a time $t_{1}$ that follows $t$, and a time $t_{2}$ which precedes $t_{1}$ and contains an event of announcing (the converb event). On this analysis, the two relative tense operators (Past and Future) cancel each other out, and the result is compatible with all three temporal readings of the converb construction: anteriority, overlap and posteriority. This is the minus of this solution, since the future operator does not force a posteriority interpretation; it only makes the structure compatible with posteriority.

Solution 3 adopts a dynamic semantics, where $-\mathrm{v}$ is an anaphoric relative past (Partee 1973; von Stechow 2009): 
$\mathrm{t}$ _c is a contextually given time interval. When the converb clause is preverbal (precedes the matrix verb), t_c is the topic time for the converb clause obtained from the previous discourse and t_c modifies the topic time for the matrix clause. When the converb clause is postverbal, however, it does not modify the TT of the matrix clause. This analysis thus takes the position of the converb and the matrix verb into account. With postverbal converbs, we start by processing the matrix clause. The relative Past in the matrix has a dynamic existential quantifier (Past: $\lambda \mathrm{T} \lambda \mathrm{t}_{1} \cdot \exists_{\text {dyn }} \mathrm{t} . \mathrm{T}(\mathrm{t})$ $\wedge t<t_{1}$ ) and operates on the ASPP ('flounce.off.PF'). At the level of TP we get a set of times $t_{1}$ such that there is a past time $t$ (with respect to $t_{1}$ ) containing an event of flouncing off. Then '- $v$ ' (cf. (26) above) operates on the ASPP ('announce.PF') resulting - at the level of ConvP - in a set of times $t_{1}$ such that $t_{-} c$ precedes $t_{1}$ and $t \_c$ includes the event of announcing. We then intersect this set of times with the set of times obtained in the matrix TP. The result we obtain is a function whose argument is the deictic time $t_{0}$ (i.e. the speech time). As a result, we get a past time $t$ (with respect to $t_{0}$ ) that includes the event of flouncing off and a past time $t_{-}$c (also with respect to $t_{0}$ ) that includes the event of announcing (i.e. the converb event). However, we must also find an antecedent for $t$ _c. We exploit the fact that the converb is postverbal and let t_c pick up anaphorically (here: intrasententially) the topic time $t$ from the matrix clause (i.e. $t \_c=t$ ). The topic time in the matrix is dynamically available as an antecedent for t_c, hence we must assume a dynamic framework and the presence of a dynamic existential quantifier in the matrix. Thus we get a topic time $t$ that precedes $t_{0}$ and includes both e (the matrix event) and e1 (the converb event), leaving the precise temporal relation between e and e1 unspecified. Accordingly, overlap, anteriority and posteriority interpretations between the events are in principle possible.

However, this dynamic account does not work for postverbal PF converbs that modify a future matrix clause (On vyjdet, hlopnuv dver'ju 'He will leave, smashing the door'), unless we insert a covert relative future (as above). Note that we will need both the explicit future in the matrix and an additional covert future in the converb clause to "cancel out" the precedence relation encoded explicitly in (26). We then get a future topic time $t$ for the matrix clause $\left(t>t_{0}\right)$, while $t \_c$ is before a future time $t^{\prime}$ ( $\left(\mathrm{t}^{\prime}>\mathrm{t}_{0}\right)$. Assuming again that $\mathrm{t}$-c picks up (anaphorically) the topic time $\mathrm{t}$ from the matrix clause, we end up with a "unique" topic time for the two clauses, viz. a future time that includes both e and e1. As before, the temporal relation between the two events is unspecified. Because of default narrative progression, the relation $\mathrm{e}<\mathrm{e} 1$ is inferred pragmatically.

\section{Conclusions}

In this article I have argued that the semantics of Russian converb constructions should be analyzed in terms of vagueness. Although the interpretation of a particular converb construction in a sentence is determined by several factors - its position in the sentence, the lexical type of the converb and the main predicate, presence of temporal adverbials, as well as some extra-linguistic factors (world knowledge, logical relations) - it is possible to specify the underlying meaning of the two converb forms: '-(j)a' converbs have the basic meaning of temporal overlap and '- $v$ ' converbs generally express the meaning of anteriority. This underlying meaning is easily detectable in some contexts (e.g. anteriority interpretation of Perfective converbs in sentence-initial position) while in other contexts the discourse and information structure can eliminate the possibility of preserving the basic meaning in favor of some other interpretation (hence, the vagueness of '-(j)a' and '-v' converbs).

More specifically, '-(j)a' (the marker of IPF converbs) is claimed to have a weak semantics: it encodes a temporal overlap of some kind (between the topic time of the converb event and the topic time of the matrix event). This analysis is consistent with our data. It is also consistent with the anteriority of '-(j)a' converbs in sentence-initial position on the factual IPF reading (IPF is pragmatically strengthened to the relation $\mathrm{e} \subset \mathrm{t}$ ), if we assume that '-(j)a' encodes in these cases the most trivial overlap relation - the identity function $\lambda \mathrm{T} \lambda \mathrm{t}$. $\mathrm{T}(\mathrm{t})$ (i.e. it has a zero semantics). We then get the result where the matrix event and the converb event are included in one and the same topic time, but the relation between e 1 and e 2 is unspecified; and there is a pragmatically strengthened relation $\mathrm{e} 1<\mathrm{e} 2$ due to the presence of temporal adverbials. 
As shown above, PF converbs are particularly sensitive to word-order (position in the sentence). In sentence-initial position '- $v$ ' always encodes a relative past tense (anteriority). In other positions, however, PF converbs typically have other non-temporal interpretations but are at the same time compatible with temporal anteriority, overlap or posteriority. The anteriority interpretation of non-initial PF converbs can be analyzed as in the case of initial converbs (cf. section 3) assuming that such PF converbs modify the topic time of the matrix sentence. In section 5 , several possible analyses of the posteriority reading are proposed. For all the three solutions, a covert relative Future is inserted in the converb clause (at LF). All of the proposed solutions have both positive and negative sides. For solution 1 we had to give up the unified analysis and assume that '-v' can have a zero semantics in cases of non-anteriority readings. On the other hand, this solution gave the most precise result (i.e. that the topic time of the converb event follows the topic time of the matrix event). In the two other solutions, it was possible to preserve the unified account of ' $-\mathrm{v}$ ' and the result was compatible with posteriority, but did not enforce the posteriority reading in the calculus.

\section{Acknowledgments}

I would like to thank my supervisors at the University of Oslo, in particular, Atle Grønn, for many discussions and knowledgeable advice. I am grateful to Cathrine Fabricius-Hansen and Bergljot Behrens for relevant comments and suggestions. I also owe special thanks to two anonymous reviewers and the audiences at the $3^{\text {rd }}$ Scandinavian $\mathrm{PhD}$ Conference in Bergen and the "Russian in Contrast” conference in Oslo.

\section{References}

Apresjan, J. 1983. O structure značenij jazykovych edinic. In Tekst i zdanie, ed. Teresa Dobrzynska and Elzbieta Janus, 313-339. Warszawa: Ossolineum

Boguslavskij, I. 1977. O semantičeskom opisanii russkich deepričastij: neopredelennost' ili mnogoznačnost'? Serija literatury i jazyka 36 (3): 270-281

Davidson, D. 1967. The Logical Form of Action Sentences. In The Logic of Decision and Action, ed. Nicholas Rescher, 105-122. Pittsburgh: University of Pittsburgh Press

Eckardt, R. 2002. Event semantics. Semantics, ed. Fritz Hamm and Thomas Ede Zimmermann, Linguistische Berichte, Sonderheft 10:91-127.

Fabricius-Hansen, C., and D. Haug. Forthcoming. Event elaboration: a survey, and some terminology. Chap. 1 in Big Events, Small Clauses. The Grammar of Elaboration, ed. Cathrine Fabricius-Hansen and Dag Haug. To appear in the series Language, Context and Cognition. Berlin: Mouton de Gruyter

Filiouchkina Krave, M. In progress. Converbs in contrast. PhD thesis, University of Oslo

Grønn, A. 2003. The Semantics and Pragmatics of the Russian Factual Imperfective. Oslo: Acta Humaniora

Grønn, A., and A. von Stechow. 2010. Some issues related to adjuncts and dynamic semantics: from tense to presuppositions (paper presented at the Centre for Advanced Study at the Norwegian Academy of Science and Letters, Oslo, August 19, 2010).

Halmøy, J. O. 1982. Le gérondif. Eléments pour une description syntaxique et semantique. Trondheim: Tapir 
Haspelmath, M. 1995. The converb as a cross-linguistically valid category. In Converbs in CrossLinguistic Perspective: Structure and Meaning of Adverbial Verb Forms - Adverbial Participles, Gerunds, ed. Martin Haspelmath and Ekkehard König, 1-55. Berlin: Mouton de Gruyter

Heim, I., and A. Kratzer. 1998. Semantics in Generative Grammar. Malden, MA: Blackwell Publishing

Klein, W. 1994. Time in Language. London: Routledge

Klein, W. 1995. A time-relational analysis of Russian aspect. In Language 71(4): 669-95

Kortmann, B. 1991. Free adjuncts and absolutes in English. Problems of control and interpretation. London: Routledge

Kratzer, A. 1998. More Structural Analogies Between Pronouns and Tenses. In Proceedings of Semantics and Linguistic Theory VIII, ed. Devon Strolovitch and Aaron Lawson, 92-110. Ithaca, New York: CLC Publications

König, E. 1995. The meaning of converb constructions. In Converbs in Cross-Linguistic Perspective: Structure and Meaning of Adverbial Verb Forms - Adverbial Participles, Gerunds, ed. Martin Haspelmath and Ekkehard König, 57-95. Berlin: Mouton de Gruyter

Nedjalkov, V. 1995. Some Typological Parameters of Converbs. In Converbs in Cross-Linguistic Perspective: Structure and Meaning of Adverbial Verb Forms - Adverbial Participles, Gerunds, ed. Martin Haspelmath and Ekkehard König, 97-136. Berlin: Mouton de Gruyter

Parsons, T. 1990. Events in the Semantics of English: A Study in Subatomic Semantics. Cambridge: MIT Press

Partee, B. 1973. Some Structural Analogies between Tenses and Pronouns in English. The Journal of Philosophy 70:601-609

Rappaport, G. 1984. Grammatical Function and Syntactic Structure: The Adverbial Participle of Russian. Columbus, Ohio: Slavica Publishers, Inc.

von Stechow, A. 2005. Semantisches und morphologisches Tempus: Zur temporalen Orientierung von Einstellungen und Modalen. Neue Beiträge zur germanistischen Linguistik 4:9-54

von Stechow, A. 2009. Tenses in Compositional Semantics. In The Expression of Time in Language, ed. Wolfgang Klein. To appear.

Stump, G. 1985. The semantic variability of absolute constructions. Dordrecht: Reidel

Weiss, D. 1995. Russian converbs: a typological outline. In Converbs in Cross-Linguistic

Perspective: Structure and Meaning of Adverbial Verb Forms - Adverbial Participles, Gerunds, ed. Martin Haspelmath and Ekkehard König, 239-282. Berlin: Mouton de Gruyter

Zaliznyak, A., and A. Šmelev. 2000. Vvedenie v russkuju aspektologiju (Introduction to Russian aspectology). Moskva: Studia Philologica

RuN corpus: http://www.hf.uio.no/ilos/english/research/projects/run/corpus/ 